\title{
A Study of Facial Index among Malay Population
}

\author{
Tahamida Yesmin, ${ }^{1}$ San San Thwin, ${ }^{1}$ Shazia Afrin Urmi, ${ }^{2}$ Mar Mar Wai, \\ Pu. Fazlin Zaini, ${ }^{1}$ and Khairil Azwan ${ }^{1}$ \\ ${ }^{1}$ Department of Anatomy, University Kuala Lumpur, Royal College of Medicine Perak, No. 3 Jalan Greentown, \\ 30450 Ipoh, Perak, Malaysia \\ ${ }^{2}$ Department of Dental Public Health, Saphena Women's Dental College, 111 DIT Road, Malibagh, Dhaka 1217, Bangladesh
}

Correspondence should be addressed to Tahamida Yesmin; tahamida.yesmin@yahoo.com

Received 17 July 2014; Accepted 12 October 2014; Published 13 November 2014

Academic Editor: Philipp Mitteroecker

Copyright (C) 2014 Tahamida Yesmin et al. This is an open access article distributed under the Creative Commons Attribution License, which permits unrestricted use, distribution, and reproduction in any medium, provided the original work is properly cited.

Facial analysis is anthropologically useful to identify the racial, ethnical, and sexual differences. The present study was done to see the sex difference and variation of facial index among Malaysian population. Cross-sectional descriptive type of study was done in Anatomy Department in UniKL RCMP which was performed on 81 Malay people (40 males, 41 females) aged 19-30 years. To measure the morphological parameters (facial height, facial width, and facial index), digital slide calliper and scale were used. There were significant differences found in all facial parameters of males compared with the females. The mean morphological facial height was $111.9 \pm 8.4$ and morphological facial width was $127.3 \pm 8.0$. The range of facial index was 67.44-106.90 for males and 75.21-97.99 for females. The total facial index was calculated according to the formula and the results obtained were analyzed statistically using the $t$-test which was statistically significant (0.003). The dominant phenotype in Malay population was mesoprosopic or round face (45\%) and least common face type was hyperleptoprosopic or very long face $(5 \%)$. There were significant variations in the face index between Malay males and females; further study with large sample size in different races in Malaysia is recommended.

\section{Introduction}

Two persons are never alike in their measurable characters [1] and hence study of intra- and interpopulation variations among different morphological characters has long been an interest of the anthropologists $[2,3]$. Anthropometry constitutes the technique of expressing quantitatively the form of the body and the sexual dimorphism refers to phenotypic characteristics that differ between males and females of the same species $[4,5]$. For evaluation of these variations it should be established for a particular population [6]. The comparison of the changes in facial index between parents, offspring, and sibling can give the clue to genetic transmission of inherited characters $[7,8]$. Human facial contour has always been an interesting subject for anatomists, anthropologists, plastic surgeons, and artists and also the identification of an individual's race is an essential component in forensic identification and reconstructive surgery [7]. Accurate facial analysis such as facial height, facial width, and facial index is essential for diagnosis of genetic and acquired anomalies for the study of normal and abnormal growth and for morphometric investigations. Facial index may be an important factor in increasing susceptibility to obstructive sleep apnea as europrosopic facial type favors the nasal breathing mode [8]. It clearly indicates that there is research vacuum in facial height, facial width, and facial index; that is why it demands more studies.

\section{Material and Method}

In this study, 81 Malay people were taken as subjects, 40 males and 41 females, with age range 19-30 years in a normal healthy state. Study was carried out with protocol presentation and followed by ethical committee clearance. Tresna digital slide caliper series: EC05 (ID: 111-103-20g), scale read up to $300 \mathrm{~mm}$ was used for measurement. The subjects were informed about the study design, its benefits, 
TABLE 1

\begin{tabular}{lc}
\hline Face shape & $\begin{array}{c}\text { Range of prosopic } \\
\text { index }\end{array}$ \\
\hline (1) Hypereuroprosopic (very broad face) & $<79.9$ \\
(2) Europrosopic (broad face) & $80-84.9$ \\
(3) Mesoprosopic (round face) & $85-89.9$ \\
(4) Leptoprosopic (long face) & $90-94$. \\
(5) Hyperleptoprosopic (very long face) & $>95$ \\
\hline
\end{tabular}

and confidentiality of the data collected. Written consent was taken from each subject. Subjects were asked to sit in a relaxed state and straight and to look forward. The morphological facial height was measured with digital slide caliper with scale from nasion (n) to gnathion (gn). Face width was measured as the straight distance between the right and left zygion (zyzy). The anatomical landmarks were defined as follows.

Nasion (n): the point on the root of the nose where the midsagittal plane cuts the nasofrontal sutures.

Gnathion (gn): the lowest point of mandible where the lower margin of the lower jaw is intersected by the midsagittal plane.

Zygion (zy): it is the most laterally placed point on the zygomatic arch.

Prosopic index $(\mathrm{PI})=($ Facial height $/$ Facial width $) \times$ 100.

Statistical analyses were done by descriptive statistics and Student's (independent) $t$-test. All the statistical analyses were done by using SPSS 17.0 version.

The above index was determined on the basis of international anatomical descriptions. Based on this index, the types of face shapes were categorized according to Banister's classification as shown in Table 1.

\section{Result}

The finding of the study is depicted in Tables 2,3 , and 4 . In general, females showed the minimal measurement as compared to males in both variables. The mean of female facial height was $107.00 \pm 8.4$ but in males it was $117.7 \pm 7.99$. The mean facial width was $129.9 \pm 7.7$ and $125.0 \pm 7.5$ in males and females, respectively. Combined male and female facial height was lower than the facial width in Malay population.

In Table 3 among Malay males the range of facial index was $67.44-106.90$ but for females it was 75.21-97.99. The mean \pm SD of facial index of males and females was $90.85 \pm$ 8.38 and $85.86 \pm 5.69$, respectively. There was a highly significant (0.003) difference in the mean value of facial index between males and females (Figures 2 and 3 ).

In Table 4 the result showed that the dominant type of facial shape for Malaysian males and females was mesoprosopic (round face), which was 50\% and 39\% for males and females, respectively. The second commonest type of facial shape for females was europrosopic (broad face) which was $24 \%$ but for males it was leptoprosopic (long face) which was

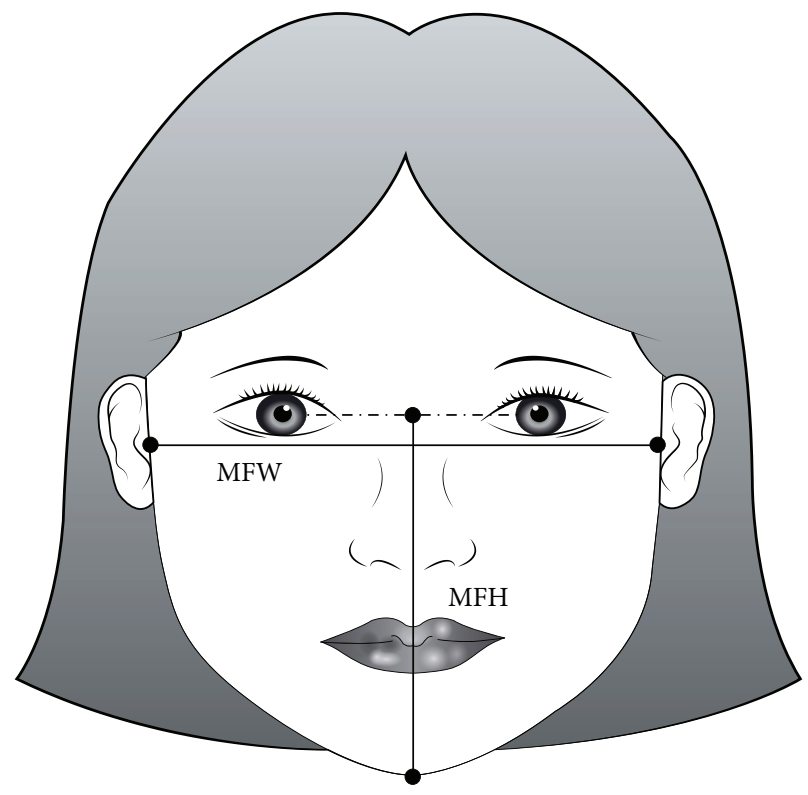

FIGURE 1: Measurement of morphological facial height (MFH) and morphological facial width (MFW).

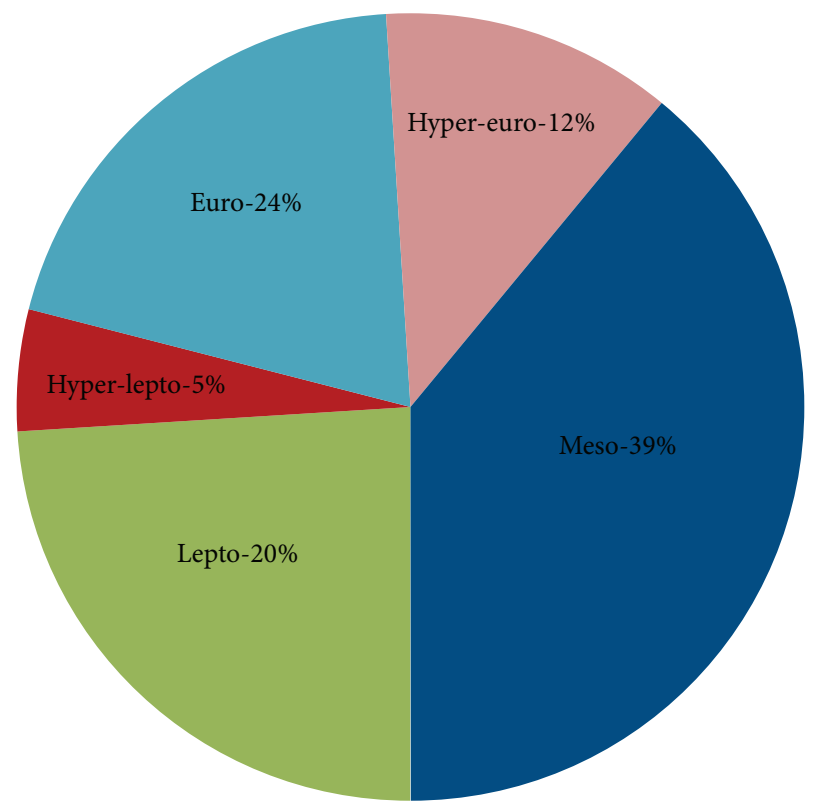

FIGURE 2: Morphological variation of facial index in females.

$20 \%$. The least common facial shape was hyperleptoprosopic (very long face) and it was 5\% for both sexes.

\section{Discussion}

This present study showed that the range of morphological facial height for Malay females was $94.6-120.9 \mathrm{~mm}$ and in Malay males was $98.54-130.8 \mathrm{~mm}$. The range of morphological facial width was $115.6-149.2 \mathrm{~mm}$ and $112.7-140.66 \mathrm{~mm}$ for females and males, respectively. In general all female values are lesser than those of males. Shetti et al. [2] had made 


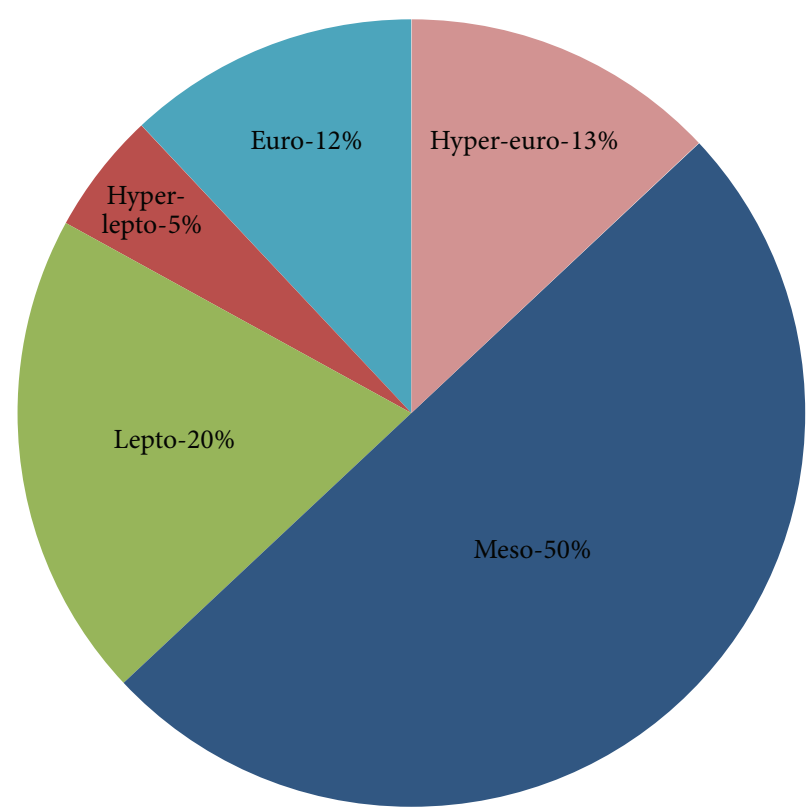

FIgURE 3: Morphological variation of facial index in males.

TABLE 2: Mean and SD of facial height and facial width of Malay males and females.

\begin{tabular}{lcccc}
\hline $\begin{array}{l}\text { Sex } \\
(n)\end{array}$ & $\begin{array}{c}\text { Facial height }(\mathrm{mm}) \\
\text { Mean } \pm \text { SD }\end{array}$ & $\begin{array}{c}\text { Range of facial } \\
\text { height }(\mathrm{mm})\end{array}$ & $\begin{array}{c}\text { Facial width }(\mathrm{mm}) \\
\text { Mean } \pm \text { SD }\end{array}$ & \multicolumn{2}{c}{$\begin{array}{c}\text { Range of facial } \\
\text { width }\end{array}$} \\
\hline Male & $117.4 \pm 7.998$ & $98.54-130.8$ & $129.9 \pm 7.711$ & $115.6-149.2$ \\
Female & $107.00 \pm 8.4$ & $94.6-120.9$ & $125.00 \pm 7.511$ & $112.7-140.66$ \\
Combined & $111.9 \pm 8.4$ & & $127.3 \pm 8.0$ & \\
\hline
\end{tabular}

TABLE 3: Mean and SD of facial index of Malay males and females.

\begin{tabular}{lccc}
\hline $\begin{array}{l}\text { Sex } \\
(n)\end{array}$ & $\begin{array}{c}\text { Facial index } \\
\text { range }\end{array}$ & $\begin{array}{c}\text { Facial index } \\
\text { Mean } \pm \text { SD }\end{array}$ & $P$ value \\
\hline Male & $67.44-106.90$ & $90.85 \pm 8.38$ & $0.003^{* * *}$ \\
Female & $75.21-97.99$ & $85.86 \pm 5.69$ & \\
\hline
\end{tabular}

*** Statistically Highly Significant.

a similar study on Malaysian students of Melaka Manipal Medical College and showed that all female values were lesser than those of males, and the mean values were also similar to the present study which were $111.9 \pm 8.4(\mathrm{MFH})$ and $127.3 \pm 8.0$ (MFW) (Figure 1). Ngeow and Aljunid carried out a similar study on young adult Malaysian Malays and found that width of the face was greater (male 121.0-153.0, female $123.0-142.0 \mathrm{~mm}$ ) than the height of the face (male 106.3134.7, female 93.9-128.9 mm) which was similar to the present study [3]. Eliakim-Ikechukwu et al. (2012), Omotoso et al. (2011), and Osunwoke et al. (2011) had carried out studies on Nigerian population on sexual dimorphism and significant difference was found between male and female facial indexes; this may be due to the male hormone testosterone which causes the changes in the shape of the face between the two sexes $[4,5,9]$. There was another study in China, done by Kurnia et al. (2012) who found that the mean facial index was $89.02 \pm 4.92$ for males and $88.52 \pm 4.89$ for females and the dominant type of face was mesoprosopic ( $40 \%$ males and $30.30 \%$ females) [8]. Another study by Salve et al. (2012) in Indian population showed that the similar result for male and as the present study as shown in Table 2 . In the Indian study, the dominant face type for males was mesoprosopic but for females it was europrosopic type, but in our study the dominant type of face for the Malays was mesoprosopic and europrosopic type of face was the second common one for Malay females. This similarity may be due to similarity of environmental condition [6]. On the other hand, Praveen Kumar Doni et al. (2013) had made a study in South Indian population and found that the dominant face type was hyperleptoprosopic, which was the least common type in Malays (5\%) [7]. Jeremić et al. (2013) carried out a study in Central Serbia and showed a similar result of sexual dimorphism which was significant as in the present study, but the dominant face type was leptoprosopic followed by mesoprosopic which was not similar to our study [10].

\section{Conclusion}

The mean facial index of Malay population has been identified. There is a significant difference present in facial index between the males and females $(P=0.003)$. The predominant face type for Malay population is mesoprosopic (50\% for 
TABLE 4: Distribution of face type in Malaysian males and females.

\begin{tabular}{lccccc}
\hline Sex & Hypereuroprosopic & $\begin{array}{c}\text { Europrosopic } \\
80-85\end{array}$ & $\begin{array}{c}\text { Mesoprosopic } \\
85-90\end{array}$ & $\begin{array}{c}\text { Leptoprosopic } \\
90-95\end{array}$ & Hyperleptoprosopic \\
$>95$
\end{tabular}

males and 39\% for females). The second common type of face for males is leptoprosopic (20\%) but for females it is europrosopic (24\%) and the least common face type for Malays is hyperleptoprosopic (5\%).

\section{Conflict of Interests}

The authors declare that there is no conflict of interests regarding the publication of this paper.

\section{References}

[1] U. Kanan, A. Gandotra, A. Desai, and R. Andani, "Variation in facial index of Gujarati males-a photometric study," International Journal of Medical and Health Sciences, vol. 1, no. 4, pp. 27-31, 2012.

[2] V. R. Shetti, S. R. Pai, G. K. Sneha, C. Gupta, and P. Chethan, "Study of prosopic (Facial) index of Indian and Malaysian students," International Journal of Morphology, vol. 29, no. 3, pp. 1018-1021, 2011.

[3] W. C. Ngeow and S. T. Aljunid, "Craniofacial anthropometric norms of Malays," Singapore Medical Journal, vol. 50, no. 5, pp. 525-528, 2009.

[4] C. Eliakim-Ikechukwu, E. Onugh, T. Bassey, and O. E. Mesembe, "Cephalofacial indices of the Ibo and Yoruba ethnic groups in Southern Nigeria," Journal of Biology, Agriculture and Healthcare, vol. 2, no. 11, 2012.

[5] D. R. Omotoso, O. O. Oludiran, and C. L. Sakpa, "Nasofacial anthropometry of adult Bini tribe in Nigeria," African Journal of Biomedical Research, vol. 14, no. 3, pp. 219-221, 2011.

[6] V. M. Salve, N. R. Thota, and A. Naralasetty, "A Study of facial (prosopic) index of Andhra Region (India) Students," Novel Science International Journal of Medical Science, vol. 1, no. 8, pp. 248-252, 2012.

[7] R. Praveen Kumar Doni, C. S. Janaki, V. Vijayaraghavan, and U. Delhi Raj, "A study on measurement and correlation of cephalic and facial indices in male of south Indian population," International Journal of Medical Research \& Health Sciences, vol. 2, no. 3, pp. 439-446, 2013.

[8] C. Kurnia, S. Susiana, and W. Husin, "Facial indices in chinese ethnic students aged 20-22," Journal of Dentistry Indonesia, vol. 19, no. 1, pp. 1-4, 2012.

[9] E. A. Osunwoke, F. S. Amah-Tariah, O. Obia, and I. M. Ekere, "Sexual dimorphism in facial dimensions of the Bini's of SouthSouthern Nigeria," Asian Journal of Medical Sciences, vol. 3, no. 2, pp. 71-73, 2011.

[10] D. Jeremić, K. Sanja, V. Maja et al., "Anthropometric study of the facial index in the population of central Serbia," Archives of Biological Science Belgrade, vol. 65, no. 3, pp. 1163-1168, 2013. 

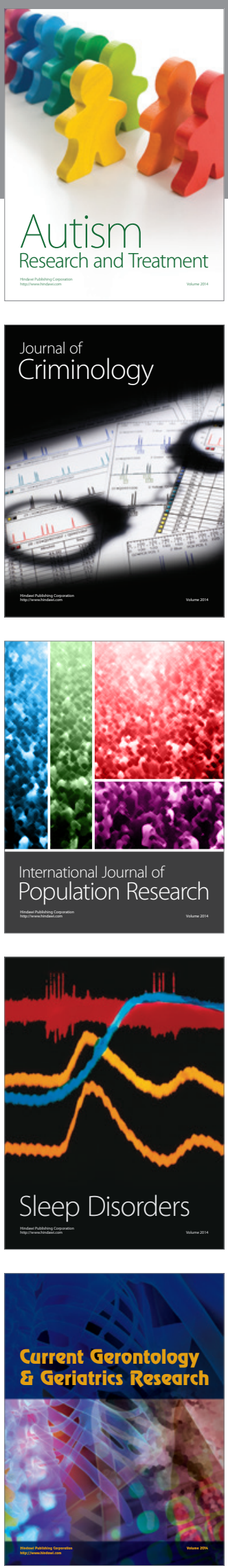
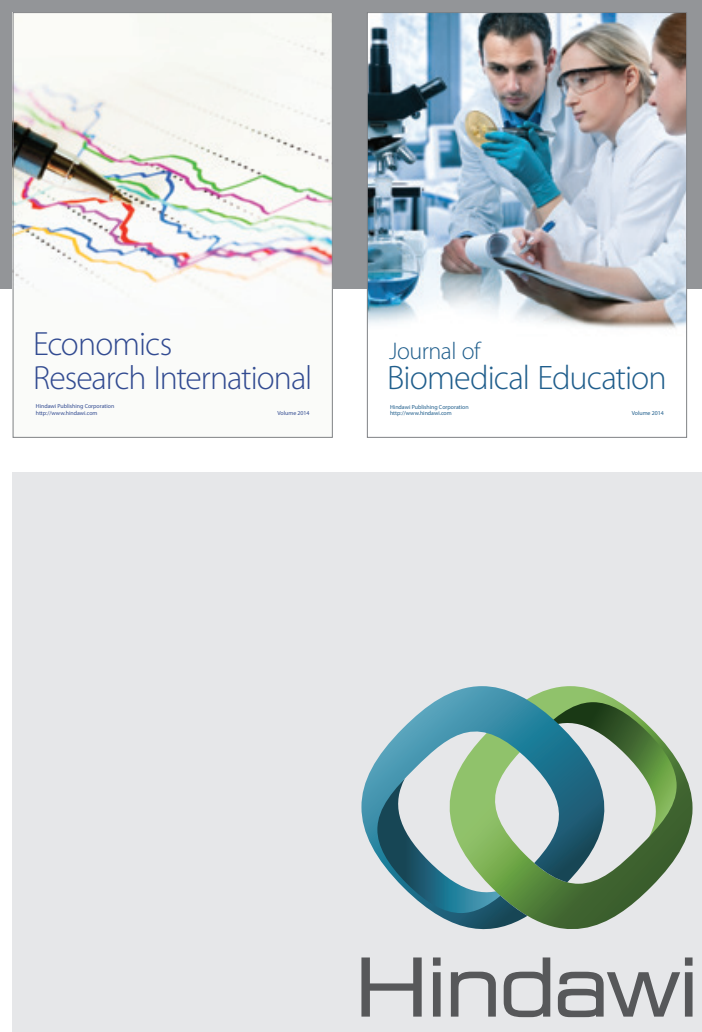

Submit your manuscripts at

http://www.hindawi.com
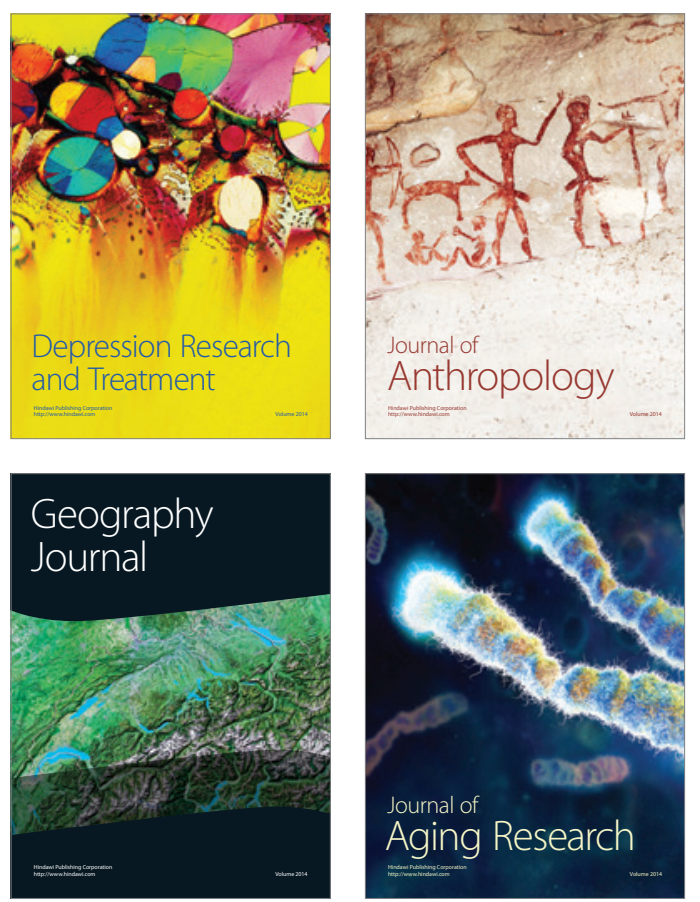
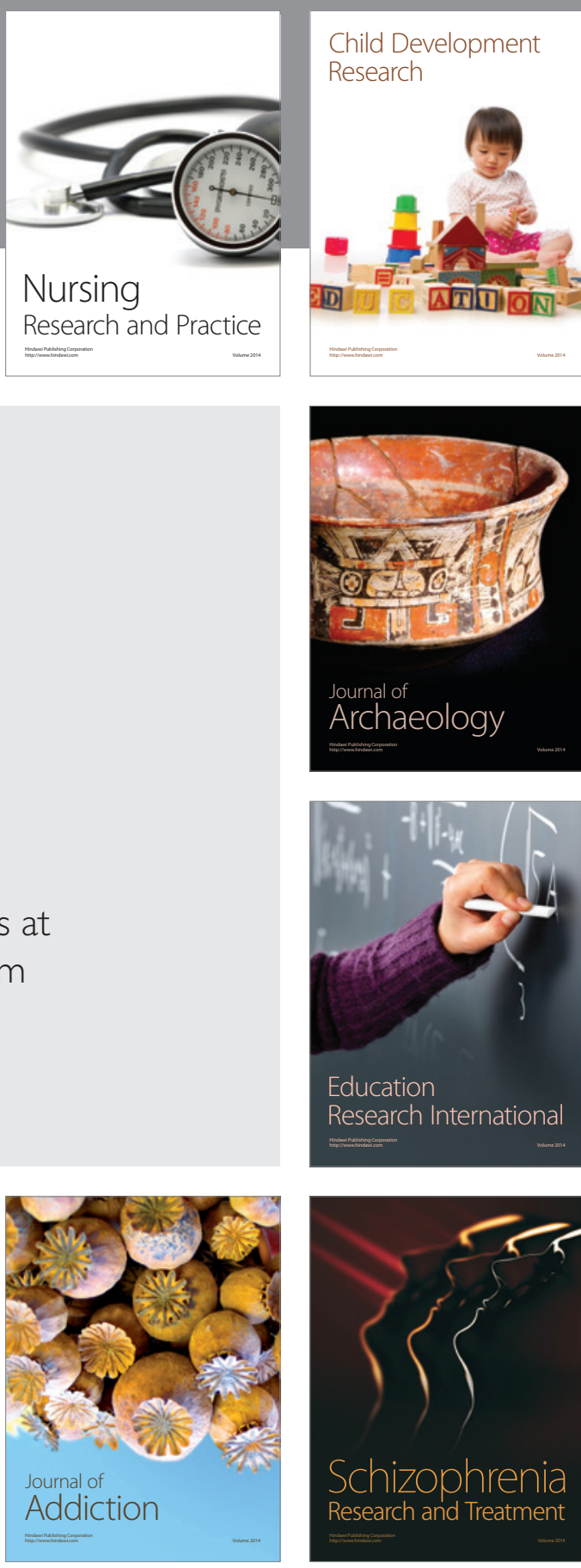

(D)
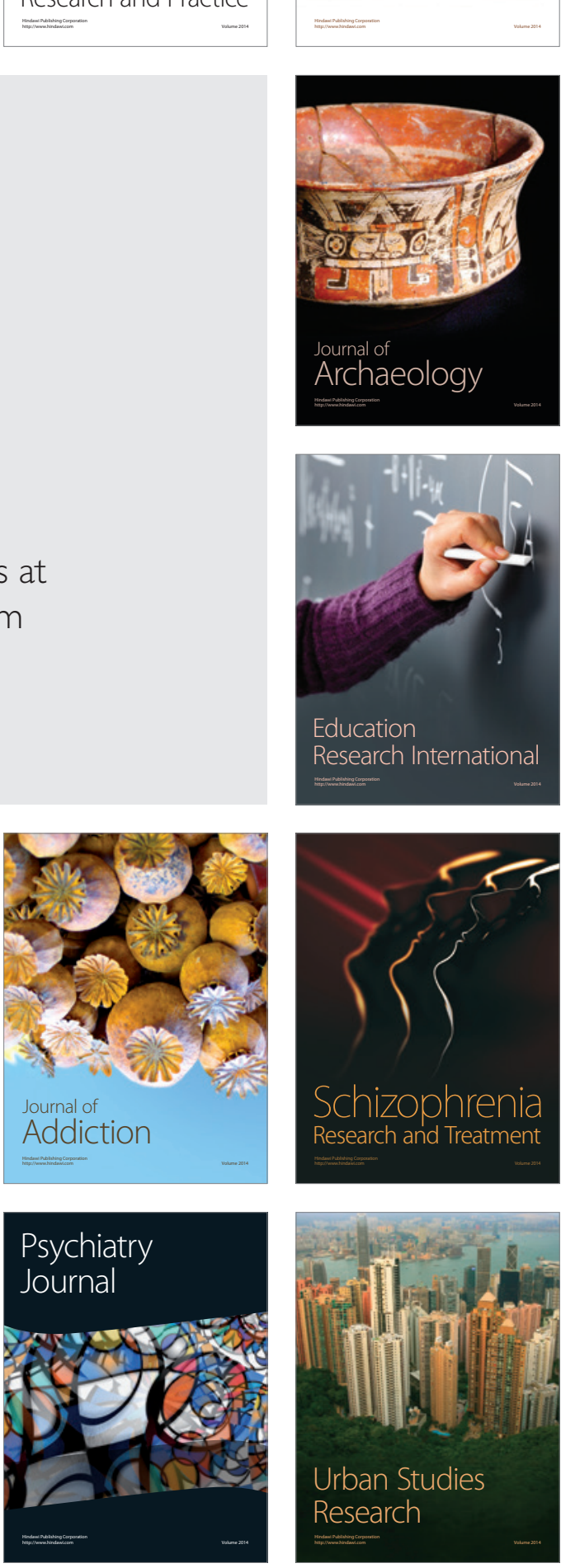